\title{
A teoria na história dos média ${ }^{1}$
}

\author{
Moisés de Lemos MARTINS ${ }^{2}$
}

\begin{abstract}
Resumo:
Tendo-se estabelecido como dispositivos tecnológicos de mediação simbólica da experiência humana e projetando um propósito emancipador de cidadania, os média constituem um projeto da modernidade. Neste artigo vamos procurar demonstrar a fecundidade da teoria na história dos média. E fá-lo-emos problematizando, antes de mais nada, a "ética da discussão, ou da comunicação", de Habermas e Apel, em que se apoia o propósito emancipador autorizado pelos média nas sociedades democráticas contemporâneas, em resultado de um vínculo essencial à linguagem, ao discurso e à comunicação. Em síntese, podemos dizer que as tecnologias da comunicação e da informação vieram deslocar o quadro teórico do debate sobre os média, do logos e do ethos para o pathos, com os média a deixarem de ser considerados como meros dispositivos discursivos, que persuadem, e a passarem a ser considerados, igualmente, como dispositivos de sons e imagens, que fascinam. Por outro lado, o processo informativo deixou de se cingir apenas a produtores e consumidores de informação, e considera, agora, igualmente, os públicos, que são hoje, também, produtores de conteúdos.
\end{abstract}

Palavras-chave: Comunicação. Discurso. Ética da discussão. Tecnologia. Teoria dos Média.

\section{Theory in the history of the media}

\begin{abstract}
:
The media is a key project of modernity, as a set of technological devices that enable symbolic mediation of human experience, which simultaneously projecting the emancipatory goal of fostering citizenship. This paper aims to demonstrate the fertile potential of theory in the history of the media. First and foremost, we will discuss "the ethics of discourse" or "the ethics of communication", as defended by Habermas and Apel, in which the emancipatory goal authorised for the media in contemporary democratic societies, is based on an essential link to language, discourse and communication. In summary, we can say that information and communication technologies have shifted the theoretical framework that underpins discussion of the media from the logos and ethos, to pathos. As a result the media can no longer be considered to be mere discursive devices, which persuade others. The media also includes devices based on sounds and images, which provoke fascination. On the other hand, the information process is no longer solely restricted to information producers and consumers, it now also encompasses audiences, who have become content producers in their own right.
\end{abstract}

Keywords: Communication. Speech. Ethics of discourse. Technology. Media theory.

\footnotetext{
I Este trabalho é apoiado por fundos nacionais através da FCT - Fundação para a Ciência e a Tecnologia, I.P., no âmbito do Financiamento Plurianual do Centro de Estudos de Comunicação e Sociedade 2020-2023 (que integra a parcela de financiamento base, com a referência UIDB/00736/2020).

2 Professor catedrático da Universidade do Minho, diretor do Centro de Estudos de Comunicação e Sociedade (CECS) da Universidade do Minho.E-mail: moisesm@ics.uminho.pt
} 


\title{
Teoría en la historia de los médios
}

\begin{abstract}
Resumen:
Los dispositivos tecnológicos se han establecido como mediadores simbólicos de la experiencia humana y proyectan un propósito emancipador en la ciudadanía, por tanto los media constituyen un proyecto de modernidad. En este artículo intentaremos demostrar la proliferación de la teoría en la historia de los medios. Y lo haremos problematizando, en primer lugar, la "ética de la discusión o comunicación", de Habermas y Apel, que respalda el propósito liberador autorizado por los medios de comunicación en las sociedades democráticas contemporáneas, como resultado de un vínculo esencial con el lenguaje, el discurso y la comunicación. En resumen, podemos decir que las tecnologías de información y comunicación han cambiado el marco teórico del debate sobre los medios, desde logos y ethos hasta pathos, con los medios que ya no se consideran meros dispositivos discursivos, que persuaden, para ser considerados, igualmente, como dispositivos de sonidos e imágenes, que fascinan. Por otro lado, el proceso de información ya no se limita a los productores y consumidores de la información, ahora también se consideran las audiencias, que hoy son igualmente productoras de contenidos.
\end{abstract}

Palabras clave: Comunicación; Discurso. Ética de la discusión. Tecnología. Teoría de los medios.

\section{Introdução - Os média e a modernidade}

Tendo-se estabelecido entre nós como dispositivos tecnológicos de mediação simbólica da experiência humana, os média constituem uma expressão da modernidade. Por sua vez, o moderno é um regime do olhar que projeta na história um propósito emancipador. Este propósito é animado por uma esperança, e no caso dos média, por uma promessa de cidadania, ou seja, por uma promessa de liberdade, igualdade e comunicação, o que quer dizer, por uma promessa de comunidade (HABERMAS, $1985 / 1990)$.

Todo o projeto de modernidade é servido, também, por uma moral do dever ser, que opera a realização das promessas formuladas. Nas sociedades democráticas contemporâneas, o propósito emancipador autorizado pelos média apoia-se, entretanto, numa "ética da discussão, ou da comunicação", para retomarmos a proposta de Habermas (1987a) e Apel (1994).

Lyotard (1993, p. 92) dirá, entretanto, que só tem sentido falar de esperança, quando a um sujeito da história é prometida uma perfeição final, ou então, quando o próprio sujeito da história se promete a si mesmo essa perfeição. Ora, segundo Habermas (1987b), é a comunicação universal, entendida como um transcendental, aquilo que figura a perfeição final, que o sujeito da história se promete a si mesmo. E por comunicação universal entende-se, em termos habermasianos, a pretensão intersubjetivamente válida à 
verdade das proposições, assim como a pretensão intersubjetivamente válida à exatidão normativa dos atos de linguagem como atos de comunicação social, e também a pretensão à sinceridade das expressões de intenções subjetivas, que fazem apelo a um reconhecimento interpessoal, e ainda, a pretensão de significado, isto é, a pretensão à validade de sentido, intersubjetivamente idêntico.

Eu diria, todavia, que a comunicação universal é o mito das origens do projeto de emancipação histórica, proposto por Habermas. E qual mito das origens, a configuração idealista da comunicação universal, em que consiste a validade intersubjetivas das proposições, estabelece a História sobre um passado imemorial, com a relação inteira e plena, sonhada no começo, a constituir-se como a promessa de um fim último. A configuração da comunicação universal participa deste imaginário moderno, um imaginário que vive no círculo hermenêutico de projetar a sua legitimidade para diante, fundando-a numa origem perdida.

\section{O sentido comunicacional do mundo da vida}

Ao colocar a questão das condições de possibilidade universais das práticas de comunicação, Habermas (1987b; 1996) configura um transcendental comunicacional, dando-lhes deste modo uma resposta idealista. No modo como entendo as coisas, a pragmática da comunicação como desafio transcendental coloca, todavia, a teoria social numa situação difícil, quando se trata de avaliar as condições atuais dos média na sociedade. É que as condições de possibilidade da comunicação em geral, ou seja, as condições universais da comunicação, supõem um plano de significação logicamente anterior à comunicação efetiva. No meu entendimento, a versão transcendental da pragmática surge como uma tentativa filosófica de ultrapassagem das Ciências Sociais, uma vez que remete para a possibilidade de um a priori com poder de constrangimento sobre a significação e a comunicação.

Ora, são as Ciências Sociais, e não a pragmática universal de Habermas (1987b), que se preocupam com os usos particulares empíricos da comunicação. Por essa razão, parece-me demasiado equívoca, por exemplo, a formulação de Quéré (1996, p. 106), que vê em Habermas "o mais filosófico dos sociólogos contemporâneos, e também o mais sociológico dos filósofos". Porque, ao interrogar a natureza da racionalidade da 
comunicação humana, Habermas não visa nenhuma Sociolinguística, nenhuma Sociologia do Discurso, nem tão-pouco uma Análise da Conversação, essas sim, tarefas sociológicas. Com efeito, a abordagem de Habermas não é empírica, mas transcendental. Quer isto dizer que se trata de especificar as condições gerais a priori de possibilidade da intercompreensão, da individuação e da sociabilidade. E os "jogos de linguagem", que Habermas, e também Apel, tomam de Wittgenstein (1953/1995), são neste contexto a condição de possibilidade desta dialética comunicacional, desenvolvida em torno de três conceitos fundamentais: o conceito de comunicação; o conceito de praxis; e o conceito de intersubjetividade.

Em Logique des Sciences Sociales et Autres Essais, Habermas (1987a, p. 430436) acolhe a abertura feita pelos trabalhos de Karl-Otto Apel à teoria wittgensteiniana dos jogos de linguagem. Apel havia-os tomado como constitutivos da organização do mundo da vida social e, ao fazê-lo, abria caminho para uma reflexão filosófica sobre as condições do acordo intersubjetivo enraizado na linguagem, e isto fora das premissas da filosofia moderna da subjetividade e da sua dialética sujeito-objeto. Habermas, ao retomar Apel, pôde falar da viragem da Teoria da Comunicação, o que lhe permitiu depois invocar apenas as normas fundamentais do discurso racional, normas essas que exprimiriam o acordo intersubjetivo enraizado na linguagem. Nestas normas residiria o único e o último fundamento desta época de crise de legitimação e de crise das tendências hegemônicas da realidade sistêmica.

Ficamos a saber, também, pela leitura da Théorie de l'Agir Communicationnel, I, que é a partir dos trabalhos de Stephen Toulmin, sobretudo de Uses of Argument (1958/2012), que Habermas (1987b, p. 39-40) vai esboçar uma teoria da argumentação que lhe permite esta aproximação transcendental e universal da linguagem. Foi ao interpretar a estrutura da linguagem como originariamente comunicacional e voltada para a intercompreensão, que Habermas pôde pretender uma "pragmática universal", uma pragmática que fundasse sistematicamente as funções da linguagem: cognitiva; regulativa; expressiva; e mesmo poética. Ou seja, ao interpretar a estrutura da linguagem como originariamente comunicacional e voltada para a intercompreensão, Habermas pôde pretender construir as condições pragmático-universais das atividades 
comunicacional e argumentativa, e pôde portanto pretender estabelecer as bases racionais da intercompreensão possível, fundada numa teoria do "agir comunicacional".

O projeto de Habermas recorre ao paradigma comunicacional para fundar uma nova forma de compreensão dos problemas da realidade social. Mas não me parece que exista, em Habermas, qualquer abordagem empírica da comunicação. O objetivo parece cingir-se a avaliar o grau de obediência das proposições que circulam no espaço público a condições estabelecidas em termos transcendentais - as já assinaladas condições do acordo intersubjetivo enraizado na linguagem.

Esta insistência nas proposições, que devem obedecer a condições prévias de verificabilidade, fazem-me pensar naquilo a que Apel (1994, p. 8) chama de "paradigma proposicional clássico" ou "paradigma semântico-referencial do logos próprio à linguagem humana". Carateriza-se este paradigma pela depreciação das funções da linguagem de natureza puramente pragmática ou comunicacional, como são as funções de expressão e de apelo, em favor da função representacionista das proposições, que são julgadas em termos de verdade e falsidade.

Quando falamos do "pragmatic turn" nos estudos da linguagem e na teoria da ação social, a referência é, antes de mais, a direção inaugurada pelo segundo Wittgenstein (1953/1995), a orientação da ordinary language philosophy, centrada na linguagem, e neste contexto, a teoria dos atos de fala, fundada por Austin e Searle. No entanto, embora seja de pragmática que falamos, quando nos referimos a Habermas, trata-se meramente de uma pragmática formal.

De acordo com Apel (1988, p. 479), do que se trata na "pragmatic turn" dos estudos da linguagem e da teoria da ação social é de uma perspetiva "em que o conceito de racionalidade da sintaxe lógica e da semântica lógica dos sistemas de linguagem foi integrado ou ultrapassado pelo conceito de racionalidade do uso humano da linguagem, quer dizer, pelo conceito de racionalidade argumentativa". Neste contexto, eu diria que a função de representação das proposições não remete unicamente para uma função simbólica, interpretável segundo os critérios da semântica referencial. Remete igualmente para as funções de expressão subjetiva e de apelo comunicativo, pertencendo a expressão subjetiva e o apelo comunicativo ao entendimento comunicacional do sentido das coisas. 
O facto de o critério de verdade presidir em Habermas (1987b) ao seu conceito de racionalidade, a ponto de podermos dizer que a sua Sociologia crítica se faz valer do caráter cognitivo dos enunciados, embora se trate de uma pretensão intersubjetivamente válida, leva-me a concluir que as funções da linguagem, de natureza propriamente pragmática ou comunicacionais, não são nele inteiramente valorizadas.

Sobre o cumprimento das funções da linguagem, de natureza propriamente pragmática ou comunicacionais, lembro uma historieta saborosa, retirada de um debate entre Apel e Popper. Conta Apel (1994, p. 7) que Popper o censurou um dia por prestar demasiada atenção à comunicação:

Você não deveria atribuir tanta importância à comunicação: é que ela é aquilo que partilhamos com os animais. Aquilo que está em jogo na linguagem humana são as proposições. É nelas que assenta a excecional faculdade humana de apresentar a verdade do mundo real.

Passe o paradoxo, penso que a atitude epistemológica de Habermas se aproxima, neste ponto, mais de Popper que de Apel. Embora invoque a pragmática, a sua teoria social dá total favor à função representacionista dos enunciados, ou seja, à pretensão à verdade das proposições, que devem obedecer a condições de verificabilidade, no caso a condições de validade intersubjetiva, em prejuízo das funções propriamente comunicacionais da linguagem. ${ }^{3}$

\section{Das palavras e ideias às imagens, sons e emoções}

O quadro teórico do debate sobre os média não pode resumir-se, no entanto, à racionalidade discursiva, ou seja, ao "conteúdo das mensagens". Identificar os média como um espaço de palavra, é, todavia, o que verificamos nas análises clássicas, por exemplo, em Tarde (1901/1986), Ortega y Gasset (1928/1989), Dewey (1927/1999) ${ }^{4}$, Lippmann (1922/1960, 1925), Adorno e Horkheimer (1947/1994), Arendt (1958/2001),

\footnotetext{
${ }^{3}$ Sobre o entendimento representacionista e o entendimento pragmático dos enunciados, escrevi "A verdade e a função de verdade nas Ciências Sociais" (MARTINS, 1994).

${ }^{4} \mathrm{~A}$ ideia de racionalidade em Dewey insiste mais na dimensão oral da linguagem do que na dimensão textual, de discurso fixado pela escrita. Escreve Dewey: "as palavras sublimes da conversação nos contactos directos têm uma importância vital que as palavras fixas e gélidas do discurso escrito não têm" (DEWEY, 1927/1999, p. 218).
} 
Habermas (1962/1986), Apel (1989), McQuail (1983/2003) e Luhmann (1970/2009), e nas análises mais recentes, designadamente, de Hall (1980/1999) e Castells (2004).

Todavia, o quadro teórico deste debate alterou-se significativamente, nas últimas décadas, desde que a experiência moderna fundamental passou a ser o digital, e por duas razões principais. Por um lado, a sociedade tornou-se de comunicação generalizada. E numa sociedade assim, o humano passou a estar, total e infinitamente, mobilizado nas suas práticas (MARTINS, 2010a) por toda a espécie de tecnologias da informação e da comunicação, sobretudo por plataformas móveis de comunicação, informação e lazer, de entre elas, iPads, tablets e smartphones; por novas formas de interação social, designadamente, redes sócio-técnicas, como o Twitter, o Facebook, o WhatsApp, o Messenger, o Instagram e o LinkedIn; e por modelos emergentes de interação, de que são exemplo as aplicações e os videojogos.

Por outro lado, deu-se "a completa imersão da técnica na vida e nos corpos", a fusão da bios com a techné, o que é particularmente evidente com as biotecnologias, os implantes, as próteses, a engenharia genética (MARTINS, 2015a, p. 343). Mas que acontece, também, no caso das novas tecnologias da imagem (MARTINS; MIRANDA; OLIVEIRA; GODINHO, 2011/2017). Aquilo a que hoje chamamos tecnologias da comunicação e da informação, especificamente a fotografia, o cinema, a rádio, o vídeo, a televisão, e sobretudo as tecnologias digitais, Internet, jogos eletrônicos, design gráfico, redes cibernéticas e ambientes virtuais, com a "convergência" de média, conteúdos e plataformas (JENKINS, 2006), funcionam em nós "como próteses de produção de emoções, como maquinetas que modelam em nós uma sensibilidade puxada à manivela" (MARTINS, 2002/2017, p. 181-186). Nos anos sessenta, McLuhan (1964) já havia insistido neste ponto: não é ao nível das ideias e dos conceitos que a tecnologia tem os seus efeitos; são as relações dos sentidos e os modos de perceção que ela transforma, pouco a pouco, e sem encontrar a menor resistência.

Mas foram Deleuze e Guattari quem fez o diagnóstico mais completo desta situação em que a técnica e a estética fazem bloco. No Anti-Oedipe, Deleuze e Guattari propõem a equivalência entre corpo, máquina e desejo. Sendo a máquina desejante e o 
desejo maquinado, é ideia de ambos que existem "tantos seres vivos nas máquinas como máquinas nos seres vivos" (DELEUZE; GUATTARI, 1972, p. 230).

É, com efeito, como um dispositivo de imagens, que aparelha tecnologicamente o mundo, que os média, assim como as redes sociotécnicas, com as quais interagem, desempenham, hoje, um papel essencial na constituição, tanto do espaço público e da opinião pública, como no funcionamento da sociedade civil, chegando mesmo a falar-se de uma "esfera pública digital” (SOUSA; PINTO; COSTA E SILVA, 2013)5. Com efeito, são os média digitais e as redes sociotécnicas que, por um lado, reativam em permanência a sociedade em rede, e que, por outro lado, alimentam o desenvolvimento de identidades transculturais e transnacionais (MARTINS, 2015a, 2015b, 2018; MARTINS; SOUSA; CABECINHAS, 2007), chegando alguns a colocar a hipótese de um espaço público e de uma opinião pública mundiais. ${ }^{6}$

Deve, todavia, salientar-se que a imagem de produção tecnológica, sendo uma expressão marcante da contemporaneidade, não é a sua única expressão. O áudio é igualmente uma das expressões que marcam a contemporaneidade. Vendo bem, vivemos numa sociedade tanto de imagens, como de sons. Ou seja, vivemos numa sociedade audiovisual. E não nos livramos de dois equívocos. É comum referirmo-nos ao nosso tempo como a era das imagens, mas equivocamo-nos ao atribuir-lhes uma espessura exclusivamente visual. E, por outro lado, voltamos a equivocar-nos, ao reduzir o audiovisual ao visual. Porque o som constitui um elemento decisivo na construção de sentido(s) no audiovisual. Como bem refere Michel Chion (1994, p. xxvi), "não vemos a mesma coisa quando ouvimos, e não ouvimos a mesma coisa quando vemos".

\footnotetext{
${ }^{5} \mathrm{O}$ espaço público e a opinião pública, como eixo normativo do mundo moderno, desenvolveu-se no Ocidente por volta do século XVII e assim se foi mantendo ao longo do tempo, "em resultado de um vínculo essencial à linguagem, ao discurso e à comunicação" (ESTEVES, 2004, p. 131). Tarde (1901/1986, p. 43 77) foi o primeiro pensador a estabelecer esta relação entre os públicos (como forma de sociabilidade típica do mundo moderno) e a comunicação e informação. Já nos anos sessenta, "ao estabelecer o princípio de publicidade, ou seja, de transparência, argumentação e abertura, como dimensão constitutiva da sociedade burguesa", Habermas (1962/1986) "faz decorrer do mesmo princípio a noção de espaço público": a copresença dos homens livres é a condição da sua deliberação em comum e a participação na deliberação coletiva é mediada pela palavra (MARTINS, 2005, p. 157). Sobre as continuidades e as transformações dos conceitos de espaço público e opinião pública na sociedade contemporânea, assim como sobre o debate "Público/Privado", ver, além de Habermas (1962/1986), Martins (2005, 2008, 2012, 2015a).

${ }^{6}$ Convocando uma primeira página do The New York Times, João Pissarra Esteves assinala mesmo "a emergência de uma segunda grande superpotência mundial - precisamente, a opinião pública" (ESTEVES, 2005, p. 25).
} 
Mas, a meu ver, a significação, seja da imagem, seja do som, não é meramente discursiva, pelo que não pode ser tomada como tal pela análise social. ${ }^{7}$

Ao processo de construção do sentido das imagens e dos sons, que assenta apenas no funcionamento da língua, interessam-lhe unicamente os processos retóricos e argumentativos, que criam persuasão. Este é, por exemplo, o ponto de vista de Roland Barthes ao elaborar uma semiótica da imagem centrada no funcionamento da língua. Daí que Barthes tenha dado tanta importância à "retórica antiga", analisando-a num texto fundamental (BARTHES, 1970). E todos os códigos não linguísticos (visuais, sonoros, gestuais, animais, objetuais...) funcionariam por analogia com a língua. "A retórica da imagem", sobre "Les pâtes Panzani", é um texto bem elucidativo, a este propósito. Nele são estudados dois sistemas de significação, fundados no funcionamento da língua, que se sobrepõem: um denotativo, ou referencial, que diz as coisas, e um outro conotativo, que as imagina (neste último caso, um funcionamento mítico) (BARTHES, 1964).

Também em termos teóricos, Joly (1994/2007) seguiu, na sua Introdução à Análise da Imagem, as pisadas da semiótica barthesiana. Podem também ser entendidos neste sentido O Olho de Deus no Discurso Salazarista (MARTINS, 1990/2016) e A Linguagem, a Verdade e o Poder. Ensaio de Semiótica Social (MARTINS, 2002/2017), obras que publiquei, a primeira em 1990 e a segunda em 2002.

Esta perspetiva semiótica, que é a perspectiva clássica da tradição francesa, de Saussure (1919), Barthes (1964) e Greimas (2002), funciona como se a imagem não fosse, ainda, a expressão da nossa cultura. Por essa razão, de um modo geral, os tratados de argumentação não se ocupam de imagens, mas de proposições, que exprimem raciocínios retóricos. Ainda no volume 16 da revista Comunicação e Sociedade (2009), que organizei com Rui Grácio, sobre "Comunicação, argumentação e retórica” (MARTINS; GRÁCIO, 2009), nenhum dos autores se ocupa de imagens, mas da racionalidade discursiva e textual. E, todavia, vamos encontrar entre eles Ruth Amossy, Wayne Brockriede, Jean

\footnotetext{
${ }^{7}$ Hartley (1992) e McQuail (1983/2003) não deixam, todavia, de assinalar que se deve a McLuhan a análise centrada na experiência dos sentidos, "em que podemos experienciar o mundo com maior ou menor imaginação visual" (MCQUAIL, 1983/2003, p. 111). Mas que a semiose da imagem não é meramente discursiva é igualmente o sentido dos textos que escrevi nos últimos anos. Veja-se, por exemplo, Crise no Castelo da Cultura (2011/2017, sobretudo, p. 187-190); e "Média e melancolia: o trágico, o grotesco e o barroco" (MARTINS, 2011).
} 
Goodwin, Christian Plantin, Enrique Castelló, Tito Cardoso e Cunha, Paulo Serra e Rui Grácio.

Mas estávamos apenas no início do processo de translação da racionalidade argumentativa para a racionalidade emocional, da ideologia para a "sensologia" $\left(\right.$ PERNIOLA, 1991/1993) ${ }^{8}$. A nova realidade que começava, entretanto, a afirmar-se tinha, todavia, como mensageiros: o look (a imagem, o aspeto, o visual); o brand ou a griffe (a marca, aquilo a que os clássicos chamavam "exemplo"); o timing (o tempo oportuno, ou o kairos); o marketing (a arte de persuadir).

Quando falamos, hoje, de participação cívica, ou seja, de espaço público e opinião pública, tem sentido deslocar o centro de gravidade da análise da racionalidade argumentativa para a racionalidade emocional. Porque o regime do pathos é, sem dúvida, muito mais consonante com o regime de produção tecnológica de imagens e sons, que é a situação a que a sociedade contemporânea está hoje sujeita. Em vez de nos ocuparmos unicamente de silogismos retóricos, fundados na verosimilhança, e das suas estratégias argumentativas, penso que há lugar para nos ocuparmos dos sonhos, ou seja, dos percursos figurativos da imagem, enfim, do imaginário (DURAND, 1969) ${ }^{9}$, ou daquilo a que Derrida (1967, p. 418-419) chamava "mitopoética", retomando a figura de "bricolage" do mito, de Lévi-Strauss, em La Pensée Sauvage.

Neste contexto, os média e as redes sociotécnicas, muito embora sejam dispositivos de palavras, que demonstram ou persuadem, por exemplo através de notícias, assim como do uso de raciocínios e slogans, são igualmente dispositivos de imagens e de sons, que nos seduzem e fascinam.

Os média e as redes sócio-técnicas confrontam os cidadãos com estratégias retóricas (conscientes); mas convocam-nos, igualmente, a uma travessia, porque constituem um lugar obsidiado por imagens e sons, que possibilitam os mais diversos percursos (inconscientes). É esse o sentido do livro que escrevi em 2011, com o título

${ }^{8}$ A "sensologia" foi tematizada por Mario Perniola no ensaio Del sentire, cuja primeira edição data de 1991. Exprime a importância crescente das sensações (e das emoções), num movimento de abandono da ideologia. Todavia, nesta passagem da ideologia para a "sensologia", Perniola vê uma experiência do que se repete, uma experiência "do já sentido", e não uma experiência original, como se fosse impossível experimentar pela primeira vez o que quer que seja.

9 Veja-se, também, neste sentido: "O discurso da identidade e o modo de enunciar a periferia" (MARTINS, 1991). 
Crise no Castelo da Cultura - Das Estrelas para os Ecrãs (MARTINS, 2011/2017). Tratase de uma proposta que dá conta da deslocação do logos e do ethos para o pathos (MARTINS, 2011/2017, p. 188-189); das proposições para as imagens; do "sun/bolé", uma imagem que reúne, para a "dia/bolé", uma imagem que separa (MARTINS, 2011/2017, p. 207); dos raciocínios para os memes; do consciente para o inconsciente; da retórica para o percurso figurativo; da persuasão para a sedução e o fascínio; de um imaginário dramático, clássico e sublime, para um imaginário trágico, barroco e grotesco (MARTINS, 2011/2017, p. 187-188) ${ }^{10}$; dos média como dispositivos discursivos, de sentido retórico, para os média como dispositivos de imagens, com memória sensorial, afetiva a e corporal; de um processo informativo com produtores e consumidores de informação, para redes sociotécnicas com tribos e públicos que são produtores de conteúdos. $^{11}$

\section{A estetização do mundo, o espaço público e a opinião pública}

A meu ver, a questão do espaço público e da cidadania inscreve-se num eixo de sentido moderno, que faz funcionar no mesmo plano a técnica e a estética. Carateriza-o, todavia, um pessimismo histórico. Sendo, entretanto, motivado por uma compreensão profunda dos limites e falhanços daquilo a que Habermas chamou "o projeto inacabado da modernidade" (ANG, 1998), esta atitude epistemológica abre alguns dos debates essenciais da contemporaneidade. Dado que não remete para normas universais que meçam todos os enunciados, este eixo de sentido faz declinações decetivas do público: é “público fantasmagórico”, para Lippmann (1925); “público simulacral”, para Baudrillard

\footnotetext{
10 Estes dois regimes do imaginário remetem para dois distintos regimes da narrativa: um regime da promessa e um regime melancólico. Do lado do regime da promessa temos narrativas com personagens clássicas, cujas formas são constituídas por linhas direitas e superfícies claras; e também temos formas dramáticas, com as personagens a viverem contradições redimidas por uma síntese; e ainda formas sublimes a indicar um mundo elevado. Do lado, do regime melancólico temos narrativas com personagens barrocas, cujas formas são constituídas por linhas curvas, dobras e superfícies côncavas e sombrias; e também temos formas trágicas, em que os personagens vivem contradições sem que nenhuma síntese as resolva; e temos ainda, formas grotescas, com personagens que são caraterizados pela desproporção e pela fealdade. Sobre o regime da promessa e o regime melancólico, ver também, por exemplo, Martins (2007a, 2011 e 2013). 11 É neste sentido que eu leio o livro editado por Oliveira \& Prata (2015), Rádio em Portugal e no Brasil: trajetória e cenários. Existe neste livro uma secção que consagra, precisamente, uma mutação da rádio, do paradigma industrial para o paradigma informacional. Chama-se "Multimodalidade e Internet".
} 
(1981, p. 42); "sobrevivência simulacral” e espectral, no caso de Bragança de Miranda (1995, p. 142).

É meu entendimento que este eixo, que combina a técnica com a estética, interroga a natureza atual da técnica. O eixo técnico-ético moraliza a técnica: por um lado, procura controlá-la, através de normas universais; por outro, promove o seu bom uso. Por sua vez, o eixo ético-estético celebra a técnica como uma remitificação da existência, jungindo arcaísmo e tecnologia. ${ }^{12}$ Em contrapartida, o eixo técnico-estético problematiza a natureza da técnica, vendo nela a realização da razão como controlo e, simultaneamente, a modelação da nossa sensibilidade e emotividade, de modo a produzir o efeito cada vez mais alargado de estetização do mundo.

$\mathrm{Na}$ era da técnica, tanto como a imagem, também o som tem capacidades expressivas e integra o atual processo de estetização do quotidiano, concorrendo para a conversão da existência em experiência sensível e emocional. Com efeito, para dar um exemplo, a rádio na Web (a "radiomorphosis") significa novos conteúdos, uma nova linguagem, novas formas de ouvir o som, com cada internauta a construir a sua própria narrativa sonora.

Entre outros debates essenciais da contemporaneidade a que este eixo da técnica e da estética procura dar resposta, assinalo as seguintes: a natureza da técnica na era do computador (HEIDEGGER, 1954/2002; MARTINS, 1998, 2007b; MIRANDA; PINTO; RIBEIRO, 2019 ${ }^{13}$ ); uma nova teoria da imagem (JENKINS, 2003; KRESS, 2010; KRESS; VAN LEUWEN, 2001; MANOVICH, 2001; MARTINS, 2010b; MARTINS; MIRANDA; OLIVEIRA; GODINHO, 2011/2017; SCOLARI, 2008, 2013; CORREIA; CERQUEIRA, 2017); o "bloco alucinatório", constituído pela ligação da técnica com a estética, com referências, por exemplo, a Benjamin (1936/1992), McLuhan (1964), Debord (1967/1992), Perniola (1994/2004); uma revisão da teoria da violência, da dominação e do controlo (AGAMBEN, 1995; DELEUZE, 1990; DELEUZE;

\footnotetext{
${ }_{12}$ Como assinala Maffesoli (2011, p. 17), "a tecnologia pós-moderna participa do reencantamento do mundo".

${ }^{13} \mathrm{O}$ debate sobre a técnica e o papel que as novas tecnologias, que incluem os média, têm na redefinição da cultura, ou seja, na delimitação do humano, é um debate que não pode esquecer o ensaio de Heidegger sobre a técnica, que encontramos em Vorträge und Aufsätze, 1954, com o título "Die Frage nach der Technik" (HEIDEGGER, 1954/2002, p. 11-38).
} 
GUATTARI, 1972, 1980; FOUCAULT, 1975, 1976, 2004); uma problematização da experiência humana e do seu progressivo empobrecimento (BENJAMIN, 1933/2005), com uma "congelação dissimilada do mundo" (DEBORD, 1967/1992, p. 200) e a reanimação de uns tantos conceitos, assim como o depuramento de outros, por exemplo, alienação, anestesiamento, simulacro, um percurso por onde passa, entre outros, Baudrillard (1981).

\section{Considerações finais}

A crítica de Habermas (1962/1986) à concepção burguesa de espaço público recaiu no facto de esse espaço constituir uma falsa universalização e de impor a necessidade de o realizar verdadeiramente. Se bem observarmos, esta tese glosa e revê a ideia de Marx sobre o fim do capitalismo: o seu advento precipita o fim da divisão entre Estado e Sociedade Civil e faz desaparecer o próprio Estado.

De um ponto de vista comunicacional, este entendimento é todavia redutor, por não atender às razões técnicas e estéticas, cuja consideração encontrámos já em McLuhan (1962, 1964). Mas é verdade que a associação de técnica e estética, que tem hoje nas redes sociotécnicas a sua expressão mais exuberante, é já acentuada por Benjamin (1936/1992) nos anos 30 do século passado, quando analisa o surgimento da fotografia, do cinema e da rádio, novos média para a época - o momento em que os fascismos europeus se implantavam. Benjamin mostra-nos que o tipo de sujeito pressuposto na época literária, um sujeito racional e auto-controlado, representa bem mais uma vontade coletiva do que os indivíduos empíricos. Quando considerados em conjunto, os indivíduos logo desaparecem, sublimados pela figura de uma "discussão" no espaço público. Entretanto, com a fotografia, o cinema e a rádio, que produzem e administram emoções, os indivíduos não são mobilizados em conjunto, mas individualmente.

Benjamin (1936/1992) privilegia esta tensão, que é interna à fotografia, ao cinema e à rádio (e, nos dias de hoje, aos média digitais, que aliás incluem a fotografia, o cinema e a rádio), e ataca a política de fascinação das massas, que resulta do uso que os poderes dominantes fazem das novas técnicas. É verdade que Benjamin reconhece às vanguardas um efeito de choque no combate à reaurização (remagificação) do mundo. Mas as novas 
técnicas, como é o caso do cinema, provocam por si mesmas esse choque, levando-nos ao "inconsciente óptico" (BENJAMIN, 1936/1992, p. 105), à realidade oculta da fantasmagoria, que tudo envolve.

No entendimento crítico de Benjamin, já não é possível voltar à cultura da autenticidade do sistema clássico. Pode, no entanto, objetar-se que o panorama mediático se alterou radicalmente de Benjamin para cá. Com o vídeo, foram tornadas possíveis novas artes, e também formas de contraprogramar as massas. E a subversão maior deu-se com o computador pessoal, com as redes informáticas e ciberespaciais, e com as redes sócio-técnicas. É meu entendimento, porém, que o debate sobre o espaço público e a opinião pública e a sua relação com os média é um debate que pode prosseguir ainda com Benjamin. Tenho, pessoalmente, a ideia de que o mundo que em Benjamin assiste alegremente à sua "própria destruição" (BENJAMIN, 1936/1992, p. 113) é, com efeito, hoje, o do espaço público colonizado pelos média digitais.

\section{Referências}

ADORNO, Theodor; HORKHEIMER, Max. Dialéctica de la ilustración. Madrid: Trotta, 1947/1994.

AGAMBEN, Giorgio. Moyens sans fin. Notes sur la politique. Paris: Payot \& Rivages, 1995.

ANG, Ien. The performance of the sponge: mass communication theory enters the postmodern world. In: BRANTS; Kees; HERMES, Joke; VAN ZOONEN, Liesbet (Eds.). The media in question. Londres: Sage, 1998. p. 77-88.

APEL, Karl-Otto. L'éthique de la discussion: sa portée et ses limites. In : Encyclopédie Philosophique Universelle. Paris: PUF, 1989. v. 1, p. 154-165.

APEL, Karl-Otto. Le logos propre au langage humain. Cahors: L’Éclat, 1994.

APEL, Karl-Otto. La rationalité de la communication humaine dans la perspective de la pragmatique transcendantale. Critique, n. 493-494, p. 579-603, 1988.

ARENDT, Hanna. A condição humana. Lisboa: Relógio d'Água Editores, 1958/2001.

BARTHES, Roland. L'ancienne rhétorique. Communications, Paris, n. 16, p. 172-229, 1970. 
BARTHES, Roland. Rhétorique de l'image. Communications, Paris, n. 4, p. 40-51, 1964.

BAUDRILLARD, Jean. Simulacres et simulation. Paris: Galilée, 1981.

BENJAMIN, Walter. A obra de arte na era da sua reprodutibilidade técnica. In:

BENJAMIN, Walter. Sobre arte, técnica, linguagem e política. Lisboa: Relógio D’Água, 1936/1992. p. 71-110.

BENJAMIN, Walter. Experiência e pobreza. Revista de Comunicação e Linguagens, n. 34-35, p. 317-321, 1933/2005.

CASTELLS, Manuel. A galáxia internet. Lisboa: Fundação Calouste Gulbenkian, 2004.

CHION, Michel. Audio-Vision: Sound on Screen. New York: Columbia University Press, 1994.

CORREIA, Maria da Luz; CERQUEIRA, Carla (Eds.). Fotografia e género.

Comunicação e Sociedade, Braga, n. 32, dez. 2017.

DEBORD, Guy. La société du spectacle. Paris: Gallimard, 1967/1992.

DELEUZE, Gilles. Pourparlers. Paris: Éditions de Minuit, 1990.

DELEUZE, Gilles; GUATTARI, Félix. L’Anti-Oedipe. Paris: Éditions de Minuit, 1972.

DELEUZE, Gilles; GUATTARI, Félix. Mille Plateaux. Paris: Éditions de Minuit, 1980.

DERRIDA, Jacques. L'écriture de la différence. Paris: Seuil, 1967.

DEWEY, John. The public and its problems. Atenas: Swallow Press, Ohio University Press, 1927/1999.

DURAND, Gilbert. Les structures anthropologiques de l'imaginaire. Paris: Bordas, 1969.

ESTEVES, João Pissarra. Espaço público. In: RUBIM, Antonio Albino Canelas (org.) Comunicação e política: conceitos e abordagens. Salvador: Edufba; São Paulo: Unesp, 2004. p. 127-180.

ESTEVES, João Pissarra. O espaço público e os media. Sobre a comunicação entre a normatividade e a facticidade. Lisboa: Colibri, 2005. 
FOUCAULT, Michel. Histoire de la sexualité, I. La volonté de savoir. Paris:

Gallimard, 1976.

FOUCAULT, Michel. Naissance de la biopolitique. Cours au collège de France 19781979. Paris: Gallimard-Seuil, 2004.

FOUCAULT, Michel. Surveiller et punir. Naissance de la prison. Paris: Gallimard, 1975.

GREIMAS, Algirdas Julius. Sémantique structurale. Paris: PUF, 2002.

HABERMAS, Jürgen. Between facts and norms: contributions to a discourse theory of law and democracy. Cambridge, Massachusetts: The MIT Press, 1996.

HABERMAS, Jürgen. O discurso filosófico da modernidade. Lisboa: Dom Quixote, 1985/1990.

HABERMAS, Jürgen. L’espace publique. Paris: Payot, 1962/1986.

HABERMAS, Jürgen. Logique des sciences sociales et autres essais. Paris: PUF, $1987 \mathrm{a}$.

HABERMAS, Jürgen. Théorie de l'agir communicationnel, I. Paris: Fayard, 1987b.

HALL, Stuart. Encoding/decoding. In: MARRIS, Paul; THORNHAM, Sue (Eds.)

Media studies: a reader. Edinburg: Edinburg University Press, 1980/1999.

HARTLEY, John. The politics of pictures. Londres: Routledge, 1992.

HEIDEGGER, Martin. A questão da técnica. Ensaios e conferências. Petrópolis: Vozes, 1954/2002. p. 11-38.

JENKINS, Henry. Convergence culture: where old and new media collide. Nova Iorque: New York University Press, 2006.

JENKINS, Henry. Transmedia storytelling: moving characters from books to films to video games canmake them stronger and more compelling. MIT Technology Review, Jan. 15, 2003. Disponível em:

http://www.technologyreview.com/biomedicine/13052/page1/. Acesso em: 02 maio 2020.

JOLY, Martine. Introdução à análise da imagem. Lisboa: Edições 70, 1994/2007.

KRESS, Gunther. Multimodality: a social semiotic approach to contemporary communication. Londres: Routledge, 2010. 
KRESS, Gunther; VAN LEEUWEN, Theo. Multimodal. The modes and media of contemporary communication discourse. Londres: Arnold, 2001.

LIPPMANN, Walter. The phantom public. Nova Iorque: Transaction Publishers, 1925.

LIPPMANN, Walter. Public opinion. Nova Iorque: MacMillan, 1922/1960.

LUHMANN, Niklas. Opinião pública. In: João Pissarra Esteves (org.). Comunicação e sociedade: os efeitos sociais dos meios de comunicação de massa. Lisboa: Livros Horizonte, 1970/2009. p. 163-191.

LYOTARD, Jean-François. Moralités postmodernes. Paris: Galilée, 1993.

MAFFESOLI, Michel. L'initiation au présent. Cahiers Européens de l'Imaginaire, n. 3, p. 14-27, 2011.

MANOVICH, Lev. The language of new media. Cambridge, Massachusetts: MIT Press, 2001.

MARTINS, Moisés de Lemos. O olho de Deus no discurso salazarista. Porto: Afrontamento, 1990/2016. Disponível em: http://hdl.handle.net/1822/49972. Acesso em: 02 maio 2020.

MARTINS, Moisés de Lemos. O discurso da identidade e o modo de enunciar a periferia. Revista Crítica de Ciências Sociais, Coimbra, n. 33, p. 203-215, out. 1991. Disponível em: http://hdl.handle.net/1822/23850. Acesso em: 02 maio 2020.

MARTINS, Moisés de Lemos. A verdade e a função de verdade nas Ciências Sociais. Cadernos do Noroeste, Braga, v. 7, n. 2, p. 5-18, 1994. Disponível em: https://hdl.handle.net/1822/25385. Acesso em: 02 maio 2020.

MARTINS, Moisés de Lemos. A biblioteca de Babel e a árvore do conhecimento. $\mathbf{O}$ Escritor, n. 11/12, p. 235-240, 1998. Disponível em: http://hdl.handle.net/1822/30068 . Acesso em: 02/05/2020.

MARTINS, Moisés de Lemos. A linguagem, a verdade e o poder - ensaio de semiótica social. Lisboa: FCG e FCT, 2002/2017. Disponível em: http://hdl.handle.net/1822/48230. Acesso em: 02 maio 2020.

MARTINS, Moisés de Lemos. Espaço público e vida privada. Revista Filosófica de Coimbra, n. 27, p. 157-172, 2005. Disponível em: http://hdl.handle.net/1822/23799. Acesso em: 02 maio 2020. 
MARTINS, Moisés de Lemos. La nouvelle érotique interactive. Sociétés, Paris, n. 96, p. 21-27, 2007a. Disponível em: http://hdl.handle.net/1822/23767. Acesso em: 02 maio 2020 .

MARTINS, Moisés de Lemos. Nota introdutória. A época e as suas ideias. Comunicação e Sociedade, Braga, n. 12, p. 5-7, 2007b. Disponível em: http://hdl.handle.net/1822/24115. Acesso em: 02 maio 2020.

MARTINS, Moisés de Lemos. Do funcionamento dos média à crise da modernidade: 0 espaço público e os seus simulacros. In: RAMOS, Murilo César ; DEL BIANCO, Nelia R. (org.). Estado e Comunicação. Brasília: UNB; São Paulo: Intercom, 2008. p. 205214. Disponível em: https://hdl.handle.net/1822/25369. Acesso em: 02 maio 2020.

MARTINS, Moisés de Lemos. A mobilização infinita numa sociedade de meios sem fins. In: ÁLVARES, Cláudia; DAMASIO, Manuel (org.), Teorias e práticas dos media. Situando o local no global. Lisboa: Edições Lusófonas, 2010a, p. 267-278.

Disponível em: http://hdl.handle.net/1822/24250. Acesso em: 02 maio 2020.

MARTINS, Moisés de Lemos. Os Cultural Studies no Instituto de Ciências Sociais da Universidade do Minho. In: MARTINS, Moisés de Lemos (Ed.). Caminhos nas

Ciências Sociais: memória, mudança social e razão - Estudos em homenagem a Manuel da Silva Costa. Coimbra: Grácio Editor, 2010b. p. 271-287. Disponível em:

http://hdl.handle.net/1822/25339. Acesso em: 02 maio 2020.

MARTINS, Moisés de Lemos. Crise no castelo da cultura. Das estrelas para os ecrãs. Coimbra: Grácio Editor, 2011/2017. Disponível em: http://hdl.handle.net/1822/29167 . Acesso em: 02 maio 2020.

MARTINS, Moisés de Lemos. Media e melancolia: o trágico, o grotesco e o barroco. In: ACCIAIUOLI, Margarida; BABO, Maria Augusta (coord.). Arte e melancolia. Lisboa: Instituto de História da Arte/Estudos de Arte Contemporânea e Centro de Estudos de Comunicação e Linguagens, 2011. v. 1, p. 53-65. Disponível em: https://hdl.handle.net/1822/24106. Acesso em: 02 maio 2020.

MARTINS, Moisés de Lemos. Média digitais: hibridez, interactividade, multimodalidade. Revista de Comunicação e Linguagens, n. 43/44), p. 49-60, 2012. Disponível em: https://hdl.handle.net/1822/25606. Acesso em: 02 maio 2020.

MARTINS, Moisés de Lemos. O corpo morto: mitos, ritos, superstições. Revista Lusófona de Estudos Culturais, Braga, v. 1, n. 1, p. 109-134, 2013. Disponível em: http://hdl.handle.net/1822/29225. http://dx.doi.org/10.21814/rlec.11.

MARTINS, Moisés de Lemos. Os Estudos Culturais como novas Humanidades. Revista Lusófona de Estudos Culturais, Braga, v. 3, n. 1, p. 341-361, 2015a. Disponível em: http://hdl.handle.net/1822/40655. Acesso em: 02 maio 2020. 
MARTINS, Moisés de Lemos. Médias digitais e lusofonia. In: MARTINS, Moisés de Lemos. (Ed.). Lusofonia e interculturalidade. Promessa e travessia. Famalicão: Húmus, 2015b. p. 27-56. Disponível em: http://hdl.handle.net/1822/396988. Acesso em: 02 maio 2020.

MARTINS, Moisés de Lemos. A lusofonia no contexto das identidades transnacionais e transcontinentais. Letrônica - Revista do Programa de Pós-graduação em Letras da PUCRS, v. 11, n. 1, p. 3-11, 2018. DOI: 10.15448/1984-4301.2018.1.30438.

MARTINS, Moisés de Lemos; GRACIO, Rui (Eds.) Comunicação, argumentação e retórica. Comunicação e Sociedade, n. 16, Famalicão, Húmus/CECS, 2009. Disponível em: https://revistacomsoc.pt/issue/view/77. Acesso em: 02 maio 2020.

MARTINS, Moisés de Lemos; MIRANDA, José Bragança de; OLIVEIRA, Madalena; GODINHO, Jacinto (Eds.). Imagem e pensamento. Coimbra: Grácio Editor, 2011/2017. Disponível em: http://hdl.handle.net/1822/29165. Acesso em: 02 maio 2020.

MARTINS, Moisés de Lemos; SOUSA, Helena; CABECINHAS, Rosa (Eds.) Lusocom: estudo das políticas de comunicação e discursos no espaço lusófono. In: LEDO, Margarita (org.) Comunicación local no espazo lusófono. Santiago de Compostela: Agacom, 2007. p. 301-310. Disponível em: http://hdl.handle.net/1822/24127. Acesso em: 02 maio 2020.

MCLUHAN, Marshall. The Gutenberg galaxy. Toronto: Toronto University Press, 1962.

MCLUHAN, Marshall. Understanding media. Londres: Routledge, 1964.

MCQUAIL, Denis. Teoria da comunicação de massas. Lisboa: Fundação Calouste Gulbenkian, 1983/2003.

MIRANDA, José Bragança de. Espaço público, política e mediação. Revista de Comunicação e Linguagens, Braga, n. 21-22, p. 129-148, 1995.

MIRANDA, José Bragança de; PINTO, José Gomes; RIBEIRO, Luís Cláudio (org.). Fundamento e imersão. Lisboa: Orfeu Negro, 2019.

OLIVEIRA, Madalena; PRATA, Nair (org.). Rádio em Portugal e no Brasil trajetória e cenários. Braga: Húmus/CECS, 2015.

ORTEGA Y GASSET, José. A rebelion das massas. Lisboa: Relógio d'Água, 1928/1989.

PERNIOLA, Mario. Do sentir. Lisboa: Presença, 1991/1993. 
PERNIOLA, Mario. O sex appeal do inorgânico. Ariadne: Lisboa, 2004/1994.

QUÉRÉ, Louis. Vers une anthropologie alternative pour les sciences sociales? In: C. BOUCHINDHOMME, Christian ; ROCHLITZ, Rainer (org.). Habermas, la raison, la critique. Paris: Cerf, 1996. p. 105-138.

SAUSSURE, Ferdinand. Cours de linguistique générale. Publié par Charles Bally et Albert Sechehaye. Paris: Payot, 1919.

SCOLARI, Carlos A. Hipermediaciones. Elementos para una teoría de la comunicación digital interactiva. Barcelona: Gedisa, 2008.

SCOLARI, Carlos A. Narrativas transmedia: cuando todos los medios cuentan. Barcelona: Deusto, 2013.

SOUSA, Helena; PINTO, Manuel ; COSTA E SILVA, Elsa (Eds.) Esfera pública digital. Comunicação e Sociedade, Braga, n. 23, 2013.

TARDE, Gabriel. La opinión y la multitud. Madrid: Taurus, 1901/1986.

TOULMIN, Stephen. The uses of argument. Cambridge: Cambridge University Press, $1958 / 2012$.

WITTGENSTEIN, Ludwig. Tratado lógico-filosófico - investigações filosóficas. Lisboa: Fundação Calouste Gulbenkian, 1953/1995.

Submetido em: 06.06.2020

Aprovado em: 28.06 .2020 